\title{
Ways to Overcome Emotional and Psychological Trauma in a Day Today Life
}

\author{
Susheelkumar V Ronad ${ }^{1 *}$, Chetan S Patali ${ }^{2}$ and Suvarna C Patali ${ }^{3}$ \\ ${ }^{1}$ Department of Psychiatric Nursing, DIMHANS Dharwad, India \\ ${ }^{2}$ Dhanush Institute of Nursing Sciences Bagalkot, India \\ ${ }^{3}$ Dhanush Institute of Nursing Sciences Bagalkot, India
}

Submission: September 25, 2018; Published: October 30, 2018

*Corresponding author: Susheelkumar V Ronad, Department of Psychiatric Nursing DIMHANS Dharwad, India

\section{Mini Review}

Psychological trauma is a sort of harm to the mind that happens because of an extremely troubling occasion. Injury is regularly the after-effect of a staggering measure of pressure that surpasses one's capacity to adapt, or incorporate the feelings required with that experience [1]. An awful accident includes one's understanding, or rehashing occasions of being overpowered that can be encouraged in weeks, years, or even a long time as the individual battles to adapt to the prompt conditions, in the end prompting genuine, long haul negative outcomes [2-5].

In the event that you've encountered to a great degree distressing or exasperating occasion that is abandoned you learning about vulnerable and sincerely of control, you may have been damaged. Mental injury can abandon you battling with irritating feelings, recollections, and tension that won't leave. It can likewise abandon you feeling numb, detached, and unfit to confide in other individuals [6]. At the point when awful things happen, it can require a significant stretch of time to get over the agony and feel safe once more. Be that as it may, with these selfimprovement methodologies and support, you can speed your recuperation. Regardless of whether the injury happened years back or yesterday, you can roll out mending improvements and proceed onward with your life.

\section{What is Emotional and Psychological Trauma?}

Enthusiastic and mental injury is the after-effect of phenomenally upsetting occasions that smash your suspicion that all is well and good, influencing you to feel defenseless in a perilous world. Horrendous encounters frequently include a risk to life or security; however, any circumstance that abandons you feeling overpowered and disconnected can be awful, regardless of whether it doesn't include physical mischief [7]. It's not the target actualities that decide if an occasion is awful, yet your abstract enthusiastic experience of the occasion. The more scared and defenseless you feel, the more probable you are to be damaged.
Enthusiastic and mental injury can be caused by:

i. One-time occasions, for example, mischance, damage, or savage assault, particularly in the event that it was surprising or occurred in adolescence.

ii. Ongoing, tenacious pressure, for example, living in a wrongdoing ridden neighborhood, fighting a hazardous sickness or horrible accidents that happen more than once, for example, tormenting, abusive behavior at home, or youth disregard.

iii. Commonly neglected causes, for example, medical procedure (particularly in the initial 3 long stretches of life), the sudden demise of somebody close, the separation of a huge relationship, or a mortifying or profoundly frustrating background, particularly on the off chance that somebody was purposely barbarous.

Adapting to the injury of a characteristic or artificial calamity can exhibit remarkable difficulties-regardless of whether you weren't straightforwardly associated with the occasion. Indeed, while it's exceptionally far-fetched any of us will ever be the immediate casualties of a fear-based oppressor assault, plane crash, or mass shooting, for instance, we're all consistently shelled by awful pictures via web-based networking media and news wellsprings of those individuals who have been [8]. Review these pictures again and again can overpower your sensory system and make horrendous pressure.

\section{Childhood Trauma and the Risk of Future Trauma}

While horrendous mishaps can transpire, will probably be damaged by an occasion in case you're as of now under an overwhelming pressure stack, have as of late endured a progression of misfortunes [9-11], or have been damaged previously-particularly if the prior injury happened in youth. Youth injury can come about because of anything that disturbs a tyke's feeling of security, including:

i. An unstable or unsafe environment 
ii. Separation from a parent

iii. Serious illness

iv. Intrusive medical procedures

v. Sexual, physical, or verbal abuse

vi. Domestic violence

vii. Neglect

Encountering injury in youth can have a serious and dependable impact. At the point when youth injury isn't settled, a feeling of dread and defenselessness continues into adulthood, setting the phase for facilitate injury [12]. Be that as it may, regardless of whether your injury happened numerous years back, there are steps you can take to beat the agony, figure out how to trust and associate with others once more, and recapture your feeling of passionate adjust.

\section{Symptoms of Psychological Trauma}

We as a whole respond in various approaches to injury, encountering an extensive variety of physical and passionate responses [13]. There is no "right" or "wrong" approach to think, feel, or react, so don't pass judgment on your own responses or those of other individuals. Your reactions are NORMAL responses to ABNORMAL occasions.

Emotional \& psychological symptoms

i. Shock, denial, or disbelief

ii. Confusion, difficulty concentrating

iii. Anger, irritability, mood swings

iv. Anxiety and fear

v. Guilt, shame, self-blame

vi. Withdrawing from others

vii. Feeling sad or hopeless

viii. Feeling disconnected or numb

Physical symptoms

i. Insomnia or nightmares

ii. Fatigue

iii. Being startled easily

iv. Difficulty concentrating

v. Racing heartbeat

vi. Edginess and agitation

vii. Aches and pains

viii. Muscle tension

Healing from Injury

Injury side effects regularly last from a couple of days to a couple of months, bit by bit blurring as you process the disrupting occasion [14]. Yet, notwithstanding when you're feeling good, you might be disturbed now and again by difficult recollections or feelings-particularly in light of triggers, for example, a commemoration of the occasion or something that helps you to remember the injury. On the off chance that your mental injury side effects don't ease up-or on the off chance that they turn out to be far more terrible-and you find that you can't proceed onward from the occasion for a drawn out timeframe, you might encounter Post-Traumatic Stress Disorder (PTSD). While passionate injury is an ordinary reaction to an irritating occasion, it progresses toward becoming PTSD when your sensory system gets "stuck" [15] and you stay in mental stun, unfit to comprehend what happened or process your feelings.

Regardless of whether a horrible accident includes passing, you as a survivor must adapt to the misfortune, in any event incidentally, of your feeling of wellbeing. The regular response to this misfortune is sadness. Like individuals who have lost a friend or family member, you have to experience a lamenting procedure. The accompanying tips can enable you to adapt to the feeling of despondency, mend from the injury, and proceed onward with your life [16].

\section{Injury Recuperation tip 1: Get Moving}

Injury upsets your body's normal harmony, solidifying you in a condition of hyper arousal and dread. And additionally consuming off adrenaline and discharging endorphins, exercise and development can really help repair your sensory system. Endeavour to practice for 30 minutes or more on generally days. Or on the other hand if it's less demanding, three 10-minute spurts of activity every day are similarly as great. Exercise that is musical and draws in both your arms and legs, for example, strolling, running, swimming, ball, or notwithstanding moving-works best [17]. Include a care component. Rather than concentrating on your considerations or diverting yourself while you work out, truly center around your body and how it feels as you move. Notice the vibe of your feet hitting the ground, for instance, or the mood of your breathing, or the sentiment of twist on your skin. Shake climbing, boxing, weight preparing, or hand to hand fighting can make this less demanding-all things considered, you have to center around your body developments amid these exercises with a specific end goal to dodge damage.

\section{Tip 2: Don't Seclude}

Following an injury, you might need to pull back from others, yet seclusion just exacerbates the situation. Associating with others eye to eye will enable you to recuperate, so endeavor to keep up your connections and abstain from investing excessively energy alone. You don't need to discuss the injury. Associating with others doesn't need to mean discussing the injury. Truth be told, for a few people, that can simply compound the situation. Solace originates from feeling drew in and acknowledged by others [18]. Request bolsters. While you don't need to discuss 
the injury itself, it is vital you have somebody to impart your sentiments to up close and personal, somebody who will listen mindfully without passing judgment on you. Swing to a confided in relative, companion, advocate, or priest. Take part in social exercises, regardless of whether you don't feel like it. Do "typical" things with other individuals, things that have nothing to do with the horrendous experience. Reconnect with old companions. In the event that you've withdrawn from connections that were once essential to you, try to reconnect. Join a care group for injury survivors. Being with other people who are confronting similar issues can help diminish your feeling of confinement and hearing how others adapt can help motivate you in your own recuperation.

Volunteer. And in addition helping other people, volunteering can be an incredible method to challenge the feeling of powerlessness that frequently goes with injury. Help yourself to remember your qualities and recover your feeling of intensity by helping other people [19]. Make new companions. In the event that you live alone or a long way from family and companions, it's vital to connect and make new companions. Take a class or join a club to meet individuals with comparative interests, interface with a graduated class affiliation, or connect with neighbours or work partners.

In the Event that Associating with Others is Troublesome...

Numerous individuals who have encountered injury feel detached, pulled back and think that it's hard to associate with other individuals [20]. In the event that that portrays you, there are a few things you can do before you next take a seat with a companion.

\section{Exercise or Move}

Bounce all over, swing your arms and legs, or simply thrash around. Your head will feel clearer and you'll see it less demanding to interface.

\section{Vocal Conditioning}

As peculiar as it sounds, vocal conditioning is an incredible method to open up to social commitment. Sit straight and just make "mmmm" sounds. Change the pitch and volume until the point when you encounter a lovely vibration in your face.

\section{Tip 3: Self-Direct your Sensory System}

Regardless of how fomented, restless, or wild you feel, realize that you can change your excitement framework and quiet yourself. Not exclusively will it help calm the uneasiness related with injury, however it will likewise induce a more prominent feeling of control.

\section{Careful Relaxing}

On the off chance that you are feeling perplexed, befuddled, or disturb, a fast method to quiet yourself is through careful relaxing. Just take 60 breaths, concentrating on each out breath.

\section{Tactile Information}

Does a particular sight, smell or taste rapidly influence you to feel quiet? Or on the other hand possibly petting a creature or tuning in to music attempts to rapidly alleviate you? Everybody reacts to tangible information a little in an unexpected way, so explore different avenues regarding diverse snappy pressure help strategies to discover what works best for you [21].

\section{Staying Grounded}

To feel in the present and more grounded, sit on a seat. Feel your feet on the ground and your back against the seat. Check out you and pick six questions that have red or blue in them. Notice how your breathing gets further and quieter $[22,23]$. Enable yourself to feel what you feel when you feel it: Recognize your emotions about the injury as they emerge and acknowledge them.

\section{Tip 4: Take Care of your Wellbeing}

\section{It's Actual}

Having a solid body can expand your capacity to adapt to the worry of injury.

\section{Get a lot of Rest}

After an awful ordeal, stress or dread may aggravate your rest designs. Be that as it may, an absence of value sleep can intensify your injury indications and make it harder to keep up your passionate adjust [22]. Rest and get up in the meantime every day and go for 7 to 9 long periods of rest every night.

\section{Keep away from Liquor and Medications}

Their utilization can compound your injury side effects and increment sentiments of despondency, uneasiness, and disconnection.

\section{Eat an all-around Adjusted Eating Regimen}

Eating little, all around adjusted suppers for the duration of the day will enable you to keep your vitality up and limit mindset swings. Evade sugary and browned nourishments and eat a lot of omega-3 fats, for example, salmon, walnuts, soybeans, and flaxseeds-to give your state of mind a lift.

\section{Diminish Pressure}

Attempt unwinding systems, for example, contemplation, yoga, or profound breathing activities. Timetable time for exercises that bring you euphoria, for example, most loved diversions.

At the Point when to Look for Proficient Treatment for Injury

Recuperating from injury requires some serious energy, and everybody mends at their own pace. In any case, if months have passed and your side effects aren't easing up, you may require proficient assistance from an injury master. 
Seek help for trauma if you're:

i. Having trouble functioning at home or work.

ii. Suffering from severe fear, anxiety, or depression.

iii. Unable to form close, satisfying relationships.

iv. Experiencing terrifying memories, nightmares, or flashbacks.

v. Avoiding more and more things that remind you of the trauma.

vi. Emotionally numb and disconnected from others.

vii. Using alcohol or drugs to feel better.

Working through injury can be alarming, excruciating, and conceivably re-damaging, so this recuperating work is best finished with the assistance of an accomplished injury expert. Finding the correct advisor may take some time. It's vital that the specialist you pick has encounter treating injury. In any case, the nature of the association with your advisor is similarly critical. Pick an injury expert you feel good with. In the event that you don't feel protected, regarded, or comprehended, discover another specialist.

\section{Ask Yourself}

i. Did you feel great talking about your issues with the advisor?

ii. Did you feel like the advisor comprehended what you were discussing?

iii. Were your worries considered important or would they say they were limited or rejected?

iv. Were you treated with empathy and regard?

v. Do you trust that you could develop to confide in the specialist?

\section{Treatment for Injury}

So as to recuperate from mental and passionate injury, you'll have to determine the unpalatable sentiments and recollections you've since quite a while ago maintained a strategic distance from, release repressed "battle or-flight" vitality, figure out how to manage compelling feelings, and reconstruct your capacity to confide in other individuals. An injury pro may utilize a wide range of treatment approaches in your treatment [23].

Physical encountering centres around substantial sensations, as opposed to musings and recollections about the horrible accident. By focusing on what's going on in your body, you can discharge repressed injury related vitality through shaking, crying, and different types of physical discharge. Psychological conduct treatment encourages you process and assess your musings and sentiments about an injury. EMDR (Eye Movement Desensitization and Reprocessing) fuses components of subjective social treatment with eye developments or different types of cadenced, left-right incitement that can "unfreeze" awful recollections.

\section{Helping a Friend or Family Member Manage Injury}

At the point when a friend or family member has endured injury, your help can be a critical factor in their recuperation. Be patient and comprehension. Mending from injury requires significant investment. Be understanding with the pace of recuperation and recall that everybody's reaction to injury is extraordinary. Try not to judge your cherished one's response against your own particular reaction or anybody else's. Offer functional help to enable your cherished one to get over into a typical schedule. That may mean help with gathering staple goods or housework, for instance, or basically being accessible to talk or tune in.

Try not to weight your adored one into talking yet be accessible on the off chance that they need to talk. Some injury survivors think that its hard to discuss what happened. Try not to compel your adored one to open up yet let them know you are there to tune in on the off chance that they need to talk, or accessible to simply hang out in the event that they don't. Help your adored one to mingle and unwind. Urge them to take part in physical exercise, search out companions, and seek after side interests and different exercises that bring them delight. Take a wellness class together or set a general get-together with companions. Try not to think about the injury manifestations literally. Your cherished one may end up furious, fractious, pulled back, or sincerely inaccessible. Keep in mind this is a consequence of the injury and might not have anything to do with you or your relationship.

\section{Helping Children Cope with Trauma}

To enable a youngster to recoup from injury, it's vital to impart transparently. Tell them that it's typical to feel frightened or irritate. Your youngster may likewise seek you for signs on how they should react to injury so give them a chance to see you managing side effects emphatically.

\section{How Kids Respond to Passionate and Mental Injury}

Some basic responses to injury and approaches to enable your youngster to manage them:

i. Regression. Numerous kids need to come back to a before arranging when they felt more secure. More youthful kids may wet the bed or need a jug; more established youngsters may fear being distant from everyone else. It's essential to comprehend, tolerant and consoling if your youngster reacts along these lines.

ii. Thinking the occasion is their blame. Youngsters more youthful than 8 tend to feel that if something turns out badly, it must be their blame. Make certain your youngster comprehends that he or she didn't cause the occasion.

iii. Sleep issue. A few kids experience issues tumbling to rest; others wake every now and again or have disturbing 
dreams. Give your kid a squishy toy, delicate cover, or spotlight to take to bed. Take a stab at getting to know one another at night, doing calm exercises or perusing. Be quiet. It might take a while before your kid can stay asleep from sundown to sunset once more.

iv. Feeling powerless. Being dynamic in a battle to keep an occasion from happening once more, written work thank you letters to individuals who have aided and looking after others can bring a feeling of expectation and control to everybody in the family.

\section{References}

1. American Psychiatric Association (2004) Practice Guideline for the Treatment of Patients with Acute Stress Disorder and Post-Traumatic Stress Disorder American Psychiatric Association, 2004.

2. Bisson J, Andrew M (2005) Psychological Treatment of Post-Traumatic Stress Disorder (PTSD) (Review). Cochrane Database of Syst Rev (3): CD003388.

3. Bleiberg KL, Markowitz JC, (2005) A Pilot Study of Interpersonal Psychotherapy for Posttraumatic Stress Disorder," American Journal of Psychiatry 162(1): 181-183.

4. Bonanno GA (2004) Loss, Trauma, and Human Resilience: Have We Underestimated the Human Capacity to Thrive after Extremely Adverse Events? Am Psychol 59(1): 20-28.

5. Bradley R1, Greene J, Russ E, Dutra L, Westen D (2005) A Multidimensional Meta-Analysis of Psychotherapy for PTSD," Am J Psychiatry 162(2): 214-227.

6. Bryant RA1, Moulds ML, Guthrie RM, Dang ST, Nixon RD (2003) Imaginal Exposure Alone and Imaginal Exposure with Cognitive Restructuring in Treatment of Posttraumatic Stress Disorder. J Consult Clin Psychol 71(4): 706-712.

7. Cohen J (2004) A Multisite, Randomized Controlled Trial for Children with Sexual Abuse-Related PTSD Symptoms. J Am Acad Child Adolesc Psychiatry 43(4): 393-402.

8. Cook Joan M, Schnurr Paula P, Foa Edna B (2004) Bridging the Gap between Post-Traumatic Stress Disorder Research and Clinical Practice: Or the Example of Exposure Therapy. Psychotherapy: Theory, Research, Practice, Training 41(4): 374-387.

9. Ehlers A, Clark D (2003) Early Psychological Interventions for Adult Survivors of Trauma: A Review. Biol Psychiatry 53(9): 817-826.

10. Ehlers A1, Clark DM, Hackmann A, McManus F, Fennell M (2005)
Cognitive Therapy for Post-Traumatic Stress Disorder: Development and Evaluation. Behav Res Ther 43(4): 413-431.

11. Edna B Foa, Terence M Keane, Matthew J Friedman, Judith A Cohen (2000) Effective Treatments for PTSD. Guilford Press, USA. pp. 658.

12. Foa EB, Cahill SP, Boscarino JA, Hobfoll SE, Lahad M (2005) Social, Psychological, and Psychiatric Interventions Following Terrorist Attacks: Recommendations for Practice and Research. Neuropsychopharmacology 30(10): 1806-1817.

13. Foa EB, Hembree EA, Cahill SP, Rauch SA, Riggs DS (2005) Randomized Trial of Prolonged Exposure for Posttraumatic Stress Disorder with and without Cognitive Restructuring: Outcome at Academic and Community Clinics. J Consult Clin Psychol 73(5): 953-964.

14. Frazier P, Tashiro T, Berman M, Steger M, Long J (2004) Correlates All Levels and Patterns of Positive Life Changes Following Sexual Assault. J Consult Clin Psychol 72(1): 19-30.

15. Lavie P (2001) Sleep Disturbances in the Wake of Traumatic Events. N Engl J Med 345(25): 1825-1832.

16. Litz BT, Williams LW, Julie B, Richard E, Charles C (2004) A TherapistAssisted Internet Self-Help Program for Traumatic Stress. Professional Psychology: Research and Practice 35(6): 628-634.

17. Marks I, Lovell K, Noshirvani H, Livanou M, Thrasher S (1998) Treatment of Post-Traumatic Stress Disorder by Exposure and/or Cognitive Restructuring: A Controlled Study. Arch Gen Psychiatry 55(4): 317-325.

18. McNally RJ (2003) Does Early Psychological Intervention Promote Recovery from Post-Traumatic Stress?" Psychological Science in the Public Interest 4(2): 45-79.

19. Pitman RK1, Sanders KM, Zusman RM, Healy AR, Cheema F (2002) Pilot Study of Secondary Prevention of Post-Traumatic Stress Disorder with Propranolol. Biol Psychiatry 51(2): 189-192.

20. Rothbaum BO, Davis M (2003) Applying Learning Principles to the Treatment of Post-Trauma Reactions. Ann N Y Acad Sci 1008: 112-121.

21. Schnurr PP, Friedman MJ, Foy DW, Shea MT, Hsieh FY, et al. (2003) A Randomized Trial of Trauma-Focused Group Therapy for PostTraumatic Stress Disorder: Results from a Department of Veterans Affairs Cooperative Study. Arch Gen Psychiatry 60(5): 481-489.

22. Schoenfeld FB, Marmar CR, Neylan TC (2004) Current Concepts in Pharmacotherapy for Posttraumatic Stress Disorder," Psychiatric Services 55(5): 519-531.

23. Ursano RJ, Fullerton CS, Norwood AE (1995) Psychiatric Dimensions of Disaster: Patient Care, Community Consultation, and Preventive Medicine. Harv Rev Psychiatry 3(4): 196-204.
This work is licensed under Creative

Commons Attribution 4.0 License

DOI: 10.19080/CTBEB.2018.17.555955

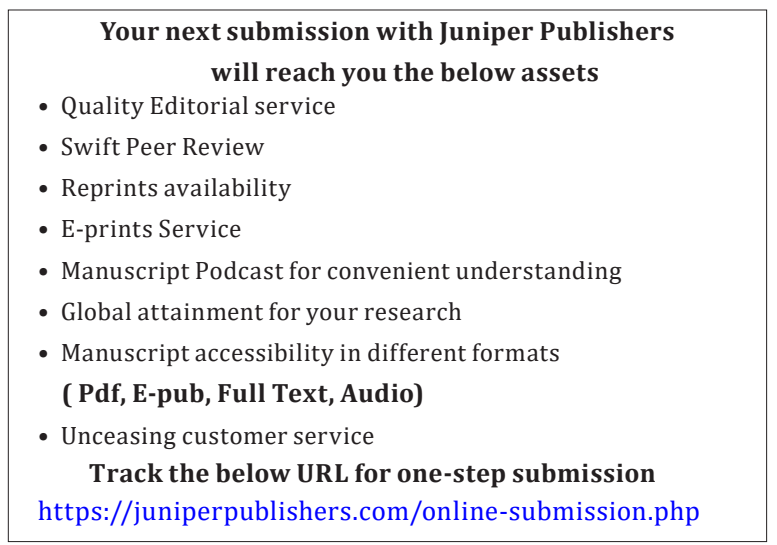

